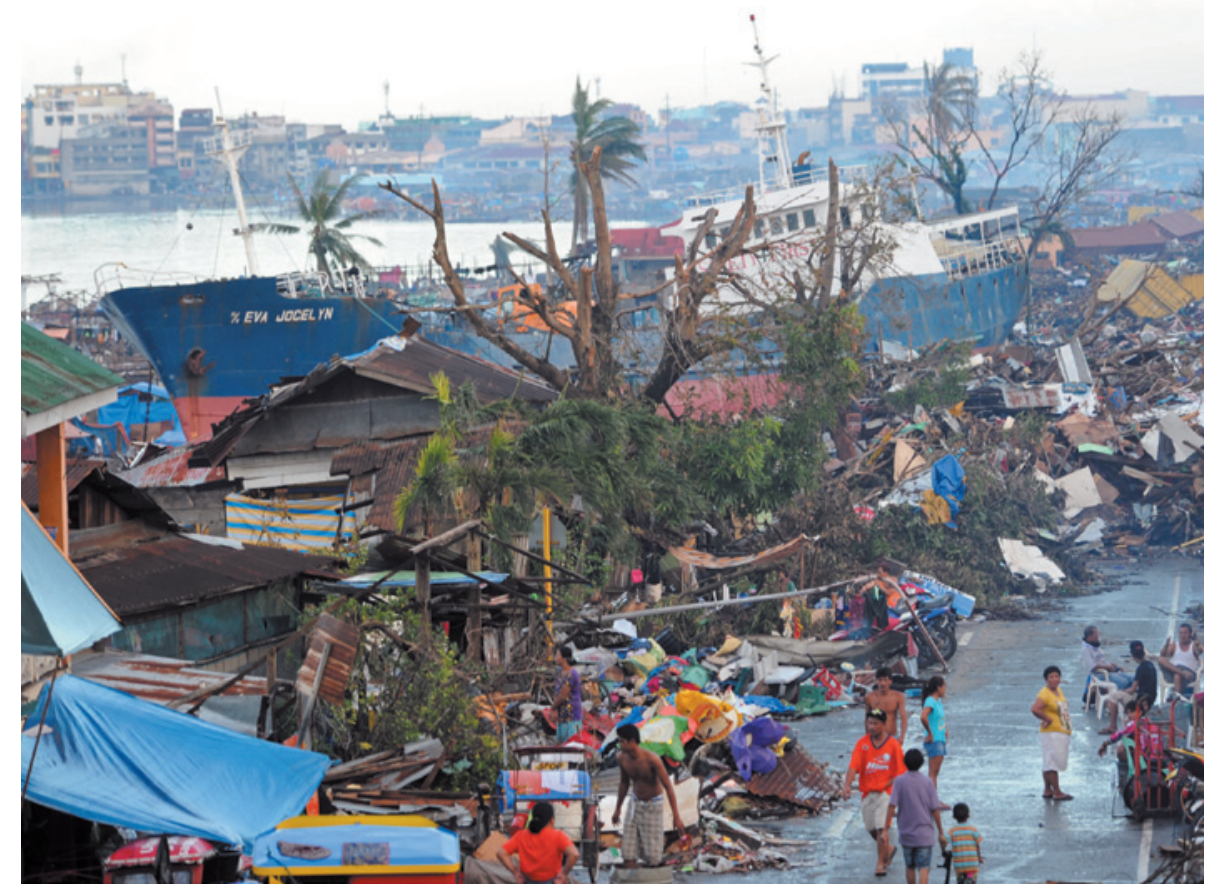

A storm surge as high as 6 metres devastated hundreds of kilometres of the Philippine coast.

\title{
NATURAL DISASTERS
}

\section{Haiyan prompts risk research}

\section{Geologists, engineers and social scientists are poised to swoop in before reconstruction gets under way.}

\section{BY SARAH ZHANG}

$\mathrm{W}$ hen typhoon Haiyan pummelled the Philippines earlier this month with winds of more than 300 kilometres per hour, it was the most intense storm to hit land in modern history. But to truly understand how unusual a storm such as Haiyan is, scientists have to turn to the geological record. That is why Davin Wallace, who studies the traces of ancient storms at the University of Southern Mississippi in Hattiesburg, is angling to go to the Philippines in the next few weeks. He hopes to calculate how often large storms strike the Philippines by comparing coarsegrained sand deposited by Haiyan with similar layers found in metres-deep sediment cores that chart thousands of years of history.

Right now, food, shelter and sanitation are the top priorities in the Philippines, where nearly 5,000 people have died and more than 4 million have been displaced as a result of Haiyan. But in a brief window of time - after the immediate humanitarian relief effort but before long-term rebuilding - scientists have a unique laboratory in which to gather data in fields as diverse as climatology, civil engineering and social science. Researchers who study natural disasters know that their work hinges on the misfortune of others, but they hope that the research can make future catastrophes less deadly.

For such time-sensitive research, being nimble is key. Timing is unpredictable, and everything happens fast, with just a few weeks from drafting a grant proposal to stepping off a plane into the disaster zone. "The logistics of just making everything work, that's $80 \%$ of your time," says Andrew Kennedy, a civil engineer at the University of Notre Dame in Indiana, who studies the threat of storm surges. "The $20 \%$ - planning for the scientific stuff - is easy by comparison."

After Hurricane Sandy battered the coast of New Jersey in 2012, Kennedy's team went door-to-door in one coastal town to detail the damage to more than 600 houses. He chose the area on the basis of post-storm satellite images that showed a wide range of damage, so that he could learn why some houses were "knocked to matchsticks" whereas others were just missing a few roof shingles. Many houses had weak connections to their foundations and could not $\stackrel{\leftrightarrow}{⺊}$ withstand the horizontal force of the storm surge. Areas not protected by high sand dunes also fared poorly. To try to understand the effect of storm surges and wave dynamics, Kennedy drops gauges onto the sea bed. Now he wants to extend his damage-prediction model, which combines ocean and building data, to the Philippines.

But with few predictable sources of grants, Kennedy knows he will have to hustle. "If it looks like something is going to hit, I call up everyone I know and ask, 'Can you give me a little bit of money?" he says. He has won small grants from the US Army Corps of Engineers and the US Geological Survey. The National Science Foundation has a dedicated programme, called Rapid Response Research (RAPID), which fast-tracks proposals requiring time-sensitive data collection. Although the review cycle is compressed from months to weeks, it still takes time for the cheque to arrive. After being told that RAPID would fund his Sandy research, Kennedy was on the ground within a month. But he only got the money more than a month after he returned.

Timing a research visit can be tricky in the post-disaster chaos, says Louise Comfort, a political scientist at the University of Pittsburgh in Pennsylvania, who wants to study the responses of Filipinos and relief organizations. After the earthquake in Haiti in 2010, she spent several days interviewing officials from governmental and non-governmental organizations. She found considerable distrust between Haitians and international aid organizations, which operated in English and often neglected to build local partnerships. Comfort says that arriving five weeks after a disaster is "Yous about right for a bal"You as a ance between letting scientist don't want to interfere with the bigger picture going on." relief workers do their jobs, and interviewing while experiences are still fresh in people's minds. "I have gone immediately after the disaster," she says. "When that's the case, you get to see things as they're happening but it's very difficult to interrupt."

For Wallace, time is also of the essence. He has to get his sampling done before reconstruction alters the sediment deposits that have washed up on shore. "Obviously there's a fine balance and I for one know this balance," he says, recalling his experience as an undergraduate in New Orleans when Hurricane Katrina devastated the city. "You as a scientist don't want to interfere with the bigger picture going on." - 